\title{
Diplomacia y ética política: textos prudenciales de Felipe II, Juan de Mariana y Joseph Creswell durante las Guerras de Religión de Francia (1562-1598) y la Guerra Anglo-Española (1585-1604) Diplomacy and Political Ethics: Prudential Texts of Philip II, Juan de Mariana and Joseph Creswell during the French Wars of Religion (1562-1598) and the Anglo-Spanish War (1585-1604)
}

\author{
A. Robert Lauer \\ The University of Oklahoma \\ ESTADOS UNIDOS \\ arlauer@ou.edu \\ [Hipogrifo, (issn: 2328-1308), 7.1, 2019, pp. 615-631] \\ Recibido: 03-01-2019 / Aceptado: 08-03-2019 \\ DOI: http://dx.doi.org/10.13035/H.2019.07.01.46
}

Resumen. A diferencia de obras estéticas, cuyas impresiones en el receptor son 'indiferentes', según Kant, los textos ético-políticos causan un surplus de afecciones. Este es el caso de reales declaraciones o proclamaciones de guerra, specula principum y peticiones laico-eclesiásticas. Analizamos el fin, siempre ambiguo; el género literario, generalmente maleable; y los múltiples efectos en receptores de obras políticas de reyes como Felipe II y Enrique IV, y eclesiásticos como los jesuitas Juan de Mariana y Joseph Creswell. Estas obras modularon la historia al suscitar diversos efectos perlocutivos en sus destinatarios durante las Guerras de Religión de Francia (1562-1598) y la Guerra Anglo-Española (1585-1604). 
Palabras clave. Felipe II de España; Enrique IV de Francia; Jacobo I de Inglaterra y VI de Escocia; Juan de Mariana; Joseph Creswell; Guerras de Religión de Francia (1562-1598); Guerra Anglo-Española (1585-1604); Conspiración de la Pólvora o Traición Jesuítica (1605); jesuitas; diplomacia; ética; política; prudencia.

Abstract. Unlike aeshtetic works, whose impressions on the receptor are 'indifferent,' according to Kant, ethico-political texts cause a surplus of emotions. This is the case with declarations or proclamations of war, specula principum, and lay-ecclesiastic petitions. Herewith we analyze the end, always ambiguous; the literary genre, often malleable; and the multiple effects on the addressees of royal political tracts penned by Kings Philip II of Spain and Henry IV of France, and Jesuit ecclesiastics like Juan de Mariana and Joseph Creswell. Their works modified history by provoking various perlocutionary effects on their readers during the French Wars of Religion (1562-1598) and the Anglo-Spanish War (1585-1604).

Keywords. Philip II of Spain; Henry IV of France; James I of England and VI of Scotland; Juan de Mariana; Joseph Creswell; French Wars of Religion (1562-1598); Anglo-Spanish War (1585-1604); Gunpowder Plot or Jesuit Treason (1605); Jesuits; Diplomacy; Ethics; Politics; Prudence.

El tema que nos ocupa versa sobre la intención y el efecto de varias obras políticas impactantes de los siglos XVI y XVII, cuyo fin parece ser ambiguo, contradictorio o mixto. En algunos ejemplos, la fidelidad oficial de los autores varía según las circunstancias del momento; en otros, el género literario inicial de estos textos se combina con otros ajenos a él; en ocasiones, los documentos prometen un fin imposible de acatar. Los escritos que nos incumben son la proclamación del 7 de marzo de 1595 de Felipe II en respuesta a la declaración de guerra de Enrique IV de Francia contra España; la promulgación de Felipe II a la armada de 1597 contra Inglaterra; las cartas de exhortación (28 y 29 de marzo de 1597) para esta invasión del jesuita Joseph Creswell, llamado «Cresuelo» en España; el espejo de príncipes intitulado De rege et regis institutione (1599) del jesuita Juan de Mariana; y «A Letter Written to the Ambassador from England» («Carta al Embaxador de Inglaterra», 1606) de Joseph Creswell a Sir Charles Cornwallis. Las susodichas obras mezclan géneros e intenciones, consignan diferentes destinatarios y constituyen obras maestras de prudencia política en relación a dos contextos bélicos: las Guerras de Religión de Francia (1562-1598) y la Guerra Anglo-Española (1585-1604).

La así llamada Declaration de Guerre faite par Philippe II. Roi d'Espagne à Henri IV. Roi de France, qu'il nomme Prince de Bearn (7 de marzo de 1595), redactada en respuesta a la Declaration de Guerre faite par Henri IV. Roi de France à Philippe II. Roi d'Espagne (16 de enero de 1595) sorprende por varias razones. El documento de Enrique IV es una declaración de guerra precisamente por la autoridad y legitimidad de las reales personas señaladas. La acusación de «Guerre ouverte» por «mettant les Catholiques en armes les uns contre les autres» es evidente, así como la lícita defensa del reino, al menos desde la perspectiva del rey francés ${ }^{7}$. Válida y

1. Henri IV, Declaration de Guerre faite par Henri IV. Roi de France à Philippe II. Roi d'Espagne, pp. 512-513. 
subsiguiente sería la guerra francesa contra España y sus partidarios por tierra y mar, así como la intención inmediata y consecutiva apuntada en el documento: invalidar pasaportes y salvoconductos y dar fin, bajo pena de muerte para los infractores, a toda comunicación, comercio, información o familiaridad entre ambos reinos.

La enérgica respuesta de Felipe II, a primera vista una declaración de guerra, aparentemente no lo es, por varias razones. Primero, Felipe le recuerda a Enrique que ambos reinos han estado en paz desde 1559 como consecuencia de la Paz de Cateau-Cambrésis, la cual obliga a España y Francia a colaborar juntos contra la herejía protestante. Después le informa que su intervención en Francia consiste en defender a los católicos de ese país: por ende, es un acto humanitario y no agresivo. Desde la perspectiva española, la intención de Enrique es arruinar a los católicos; la del Rey Prudente, socorrerlos, así como a sus aliados y confederados. España solo desea la preservación de la fe católica, tanto en Francia como en el mundo, y la paz con toda la gente de bien. Por ende, el rey de España no está en guerra con Francia ni está dispuesto a romper la paz que ha existido desde el reinado de Enrique II. Además, y este es el punto principal, según el Papa, Enrique, Príncipe de Bearne, por su herejía, no puede ser un rey legítimo y, consiguientemente, no puede romper la ley del reino. Él y sus aliados son «Ennemis publics» y deben ser tratados como tales, por mar y tierra².

La refutación de Felipe II invalida así la supuesta declaración formal de Enrique IV. A la vez, justifica la intervención española en Francia por razones humanitarias, las cuales tendrían un fundamento legal bajo la ley de naciones ${ }^{3}$. Al rescindir la legitimidad de Enrique, se invalida también no solo la declaración del mismo sino su título real. Al llamársele enemigo público, término en código para 'tirano', el documento sirve para acusarlo de hacer la guerra contra su propia gente, la cual tendría derecho a defenderse $e^{4}$. En efecto, Felipe II declara que el príncipe de Bearne, por su agresión, puede ser legalmente destituido, según las ideas políticas reinantes ${ }^{5}$. La carta de Felipe es pues una proclamación que justifica la defensa de una población en una situación hostil; es también una justificación de la inminente desposesión y posible muerte de un tirano o enemigo público.

2. Philippe II, Declaration de Guerre faite par Philippe II. Roi d'Espagne à Henri IV. Roi de France, qu'il nomme Prince de Bearn, p. 516.

3. Esta sería la opinión del jesuita Francisco Suárez en su Defensio fidei catholicae (1613). Ver Suárez, Defense of the Catholic Faith, p. 719 (IV, 33, 22): «each man has the right of repelling force with force, not only when it is done against his own body but also if it be done against any member». Consúltese también Lauer, 1995, pp. 203-204, y Lauer, 1987, pp. 68-69. Asimismo, Lesaffer, 2017, p. 104, quien compara las cartas de Enrique IV y Felipe II, indica que la del segundo constituiría un tipo de guerra justa, la cual tiene que ver con la ley natural de naciones.

4. Ver Mariana, La dignidad real y la educación del rey, p. 79 (I, 6): «Pues es [el tirano] un enemigo público que provoca todo género de males a la patria y merece verdaderamente el nombre de tirano, y no sólo puede ser destronado, sino que puede serlo por cualquier medio, incluso con la misma violencia con que él arrebató el poder».

5. Esta es la idea de Mariana en De rege, I, 6, y Suárez en Defensio, 4, 33, 22. Respecto a esta tradición en otros pensadores católicos, ver Lauer, 1987, cap. 4, pp. 49-69. 
Aunque Enrique IV se había convertido al catolicismo el 25 de julio de 1593, el papa Clemente VIII todavía no había levantado la excomunión por no estar seguro de la sinceridad del estadista. Después del regicidio en 1589 de Enrique III de Valois, primo del príncipe de Bearne, España había reconocido al arzobispo de Ruan, Carlos de Borbón, como rey legítimo de Francia. Tras la muerte de Carlos «X» en 1590, Felipe II deseaba resolver la crisis de la real sucesión en Francia, recomendando a los Estados Generales de París en 1593 la elección de la infanta Isabel Clara Eugenia, nieta de Enrique $\|^{6}$. Carlos «X» había sido el último rey católico legítimamente reconocido por los Guisa ${ }^{7}$ y Felipe II. La súbita retractación de Enrique IV en 1593 invalidó lo que habría sido un cambio de régimen. No obstante, tras la confirmación papal de la reconciliación del rey en agosto de 1595, seis meses después de la nodeclaración de guerra de Felipe II, y tras una subsiguiente derrota militar española contra tropas francesas e inglesas en Amiens en 1597, España se ve obligada a retirar su ayuda humanitaria. Por medio de la Paz de Vervins del 2 de mayo de 1598, España reconocía a Enrique IV como rey de Francia y, de este modo, se ponía fin a las Guerras de Religión de ese reino. Por consiguiente, la no-declaración de guerra de Felipe II últimamente tuvo el efecto deseado: reafirmar la paz y forzar al enemigo público a convertirse en rey legítimo 8 .

Sin embargo, la historia no termina ahí. En 1609, el futuro regicida François Ravaillac empieza a tener visiones divinas que le indican que debe amonestar a Enrique IV a convertir a los hugonotes al catolicismo, pese al Edicto de Nantes del 13 de abril de 1598 que garantizaba libertad de conciencia y de culto. Al enterarse de una inminente invasión por parte del rey de Francia de los Países Bajos Españoles, Ravaillac, el 14 de mayo de 1610, decide poner fin a la vida del rey. Muere así Enrique IV, al menos en los ojos de Ravaillac, como el tirano que la no-declaración de guerra de Felipe II había señalado anteriormente, convirtiéndose ese documento ahora en

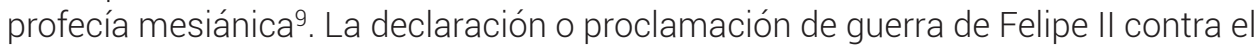
príncipe de Bearne había llegado a su última traslación posible.

6. Ver Lesaffer, 2017, p. 113. Esta también había sido la idea de Cresuelo, 29 de marzo de 1597, párrafo 7 . 7. Benedict, 2006, p. 99, menciona la posición moderada de Catalina de Médici (reina consorte de Francia entre 1547 y 1559) y los hermanos Carlos (cardenal de Lorena) y Francisco (duque de Guisa), respecto a la herejía en Francia entre 1560 y 1562. Sin embargo, la Masacre de Vassy del $1^{\circ}$ de marzo de 1562 , en la cual 63 hugonotes mueren, inicia la primera guerra civil (hasta 1598) de las así llamadas Guerras de Religión de Francia. Para detalles minuciosos sobre este conflicto, ver el excelente artículo de Lesaffer, 2017; asimismo, es imprescindible la valiosa aportación al respecto de Vázquez de Prada, 2004. 8. Esta sería la tesis de Vázquez de Prada, 2004.

9. Sobre el impacto de la noticia del asesinato de Enrique IV en España, ver el importante artículo de Usunáriz, 2016, pp. 453-472. 


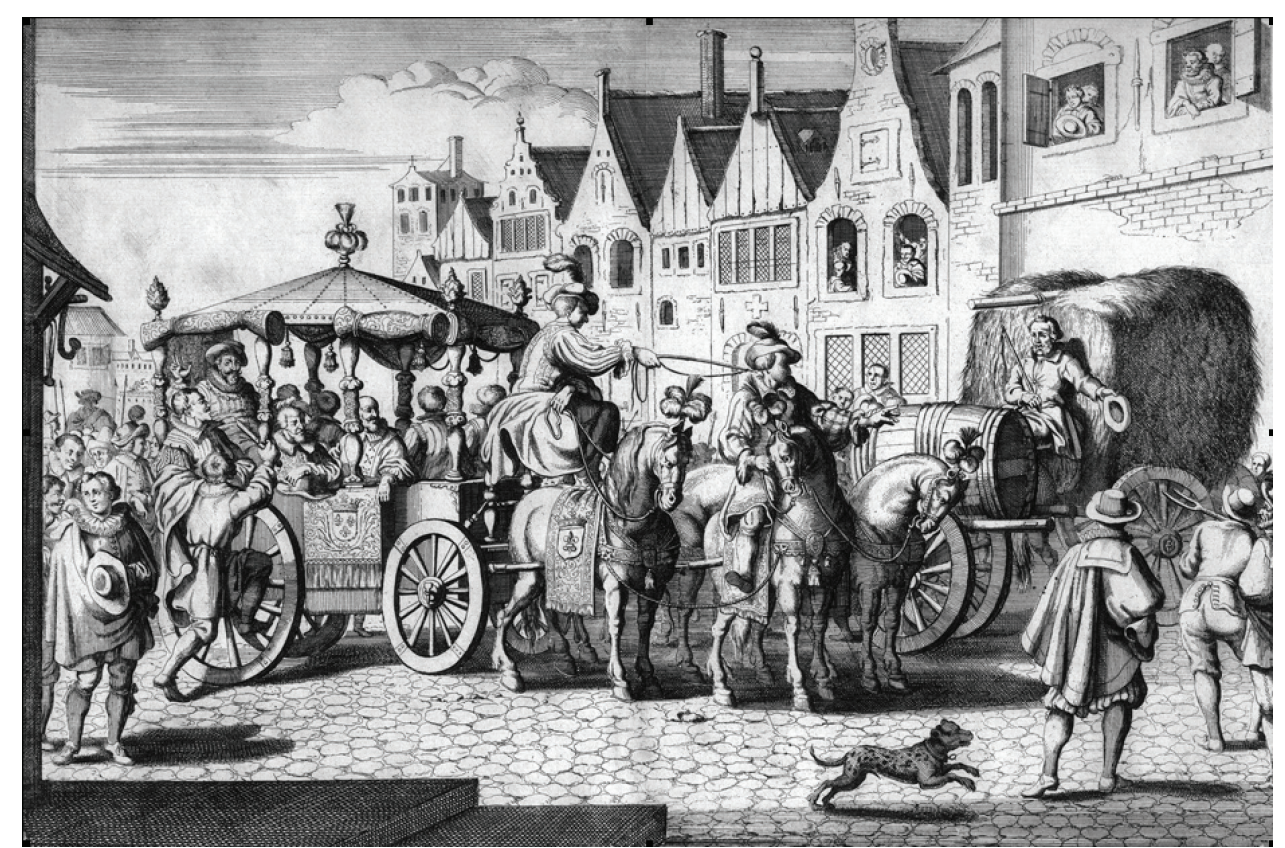

El asesinato de Enrique IV según un grabado de Gaspar Bouttats (Londres, National Portrait Gallery)

Otros documentos curiosos sobre la Guerra Anglo-Española de 1585-1604 son la llamada de Felipe II a la tercera armada española de 1597 para una futura invasión de Inglaterra y las cartas de ponderación al respecto del 28 y 29 de marzo de 1597 del jesuita inglés Arthur («Joseph») Creswell (1557-c. 1623). En Madrid, Creswell, quien firmaba su nombre «Cresuelo» en su correspondencia en español, había hecho saber al Rey Prudente la necesidad de una declaración de este tipo para refinar las intenciones del rey de España en una inminente intrusión en el Reino Unido ${ }^{10}$. Después de 1588, año de la primera Grande y Felicísima Armada, España había enviado una segunda poco afortunada armada en 1596. La de 1597 sería la tercera contra este reinado. La proclamación de Felipe II fue redactada, aprobada e impresa en España en 1597. No obstante, ninguna copia en inglés ha sobrevivido, como indica el jesuita contemporáneo Albert J. Loomie ${ }^{11}$. Sin embargo, contamos con una traducción al español fechada el 7 de noviembre de 1597, con anotaciones adicionales del padre Cresuelo que, aparentemente, fueron ignoradas ${ }^{12}$.

La proclamación es un documento insólito. El Consejo de Guerra había advertido a Felipe II de las pérdidas considerables acaecidas recientemente en Francia y los Países Bajos. Otrosí, 82 barcos de Inglaterra y las Provincias Unidas, con 8.000 soldados a cargo del Conde de Essex y el afamado militar inglés Francis Vere, ha- 
bían saqueado Cádiz el 30 de junio de $1596^{13}$. Esta había sido la tercera incursión inglesa en territorio español. En una proclamación del Conde de Essex, este había aclarado su propósito: debilitar al rey Felipe en su propio reino para proteger la Iglesia anglicana en el Reino Unido ${ }^{14}$. Frente a este tercer ataque inglés, Felipe II se sentía obligado a mandar una tercera armada contra Inglaterra. Sin embargo, España era consciente de que para triunfar se requeriría apoyo local en ese reino ${ }^{15}$. Por ende, el pregón o proclamación de hostilidades se convertía, insólitamente, en una petición.

La proclamación despunta con una justificación religiosa global en que se acusa a los así llamados usurpadores que gobiernan Inglaterra de instar a los turcos y otros infieles a atacar la cristiandad. Aunque las tropas españolas invasoras quieren mantener la paz con los católicos, también desean quitar «the brutal and cruel yoke wherewith they are burdened» ${ }^{16}$. Por ende, España viene a asistir al Parlamento inglés a restaurar leyes y costumbres así como a establecer un mejor sucesor del reino (Isabel I, la putativa Reina Virgen, había reinado desde 1558 y moriría en 1603). Se cambiarán también a los magistrados y gobernadores herejes hasta que el Parlamento decida qué hacer. Se arrestará a quienes oprimen a los católicos. Se mantendrán las casas nobles ancestrales. También se tratará bien a quienes se retiren del combate o no participen en él, premiando a quienes se rebelen para restaurar su libertad. Los soldados no violarán la disciplina militar ni causarán actos de violencia o retribución. Se perdonará a quienes capturen a William Cecil, barón de Burghley, el privado más íntimo de la reina. También se prohíbe la violencia contra la reina Isabel. Se protege así la fe católica y se establece la tranquilidad entre las naciones y la paz y acuerdos comunes. Se restablecerá asimismo el comercio y las buenas relaciones y la amistad entre los dos reinos, como anteriormente existían.

El documento es extraordinario y, en efecto, tiene varios destinatarios, entre ellos, los ingleses, quienes habrían sido sojuzgados si la armada hubiera desembarcado, y las fuerzas ocupantes, a quienes se les prohibía usar violencia innecesaria. Por ende, el pregón es, simultáneamente, una declaración de guerra contra los usurpadores herejes del reino inglés y una petición para que el enemigo o amigo invadido acepte las condiciones del invasor o libertador. Se podría opinar que España no deseaba un cambio de régimen. Como recuerda Loomie, el objetivo de la primera armada de 1588 no era conquistar Inglaterra sino poner fin a las intervenciones inglesas (y holandesas) en los asuntos de España ${ }^{17}$. Si aceptáramos que esa fuera la intención filipina en 1597, se entendería por qué se menciona que un inminente cambio de régimen lo llevaría a cabo no España sino el Parlamento inglés. Sin embargo, una anotación de Creswell indica que la intención filipina era similar a la intentada en Francia: instaurar a la infanta Isabel Clara Eugenia en el trono inglés: «For many reasons it seems best not to indicate the right of the Lady Infanta until

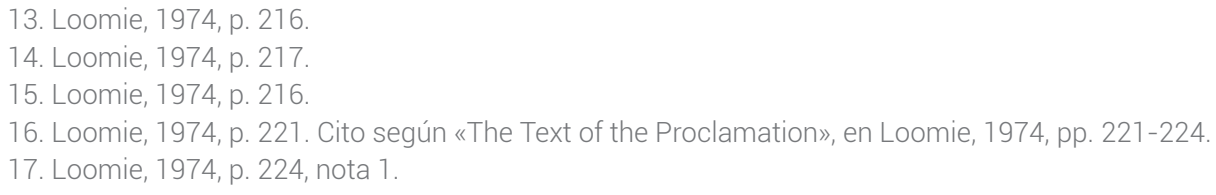


the Catholic party is superior» ${ }^{18}$. La carta del 29 de marzo de 1597 a Felipe II no deja lugar a dudas de que el cambio de régimen sería permanente: «tanto más se asentará aquella corona en la cabeza de la serenísima Infanta y de sus sucesores [énfasis mío], pues por esta vía el estado se subordinará perfectam<en>te a la religión y cobrará fuerça y estabilidad della, que es el mayor bien que en cualquier reino cristiano se puede pretender» ${ }^{19}$. Se convierte así este acto humanitario en uno de encubierta agresión.

Por las mismas razones que ocurrieron en 1596, la armada española de 1597 no llevó a cabo las acciones previstas. La súbita muerte de Isabel I, la ascensión al trono del rey Jacobo en 1603, dispuesto a poner fin a las hostilidades entre Inglaterra y España, y la subsiguiente falta de interés de parte del Consejo de Estado de seguir adelante con la invasión de Inglaterra, fueron factores para que la proclamación de 1597 nunca fuera empleada. Su existencia, sin embargo, parece demostrar la verdadera intención de España respecto a Inglaterra, al menos en 1597. El Tratado de Londres de 1604 pondría fin a la Guerra Anglo-Española (1585-1604), guerra que duró 19 años y que jamás fue formalmente declarada. Curiosamente, España obtuvo entonces los propósitos que había deseado en 1588 si la primera Grande y Felicísima Armada hubiera tenido éxito: el fin de la ayuda inglesa a los holandeses, el final de la piratería y la restauración del transporte de mercancía española por el Canal de la Mancha. España renunciaba a tratar de imponer un rey católico en Inglaterra, el cual no había sido el propósito original en 1588, pero que el desaparecido, salvo en la traducción, pregón de 1597 parece demostrar lo contrario. La conversión de Inglaterra, como en Francia, parece también haber sido uno de los propósitos de las diferentes armadas, según menciona el jesuita Creswell en sus cartas del 28 de marzo de 1597 («La conversión de aquel reino [de Inglaterra] es cosa digna de consideración») ${ }^{20}$ y 29 de marzo de 1597 («Con muchas y evidentes señales ha declarado Dios $n<$ uest>ro $S<e n ̃>0 r$ y se va declarando cada día, que es servido redimir el reino de Inglat<err $>$ a otra vez a n<uest $>$ ra $s<a n>t a$ fe» $)^{21}$. Estamos pues ante un documento de auténtica Realpolitik.

Respecto a nuestro tercer documento, De rege et regis institutione (1599) del jesuita español Juan de Mariana, publicado un año después de las Guerras de Religión de Francia, sería insólito, acaso, afirmar que no fuera un manual de instrucción. Luis Sánchez Agesta, el más reciente traductor de este escrito, afirma que «Traducimos literalmente 'Regis institutione', de acuerdo con el sentido pedagógico que Mariana quiso asignar a su obra» ${ }^{22}$. Por ende, este editor traduce el título del jesuita como La dignidad real y la educación del rey. No obstante, el término institutione, de institutio, tiene otros significados, entre ellos, establecer, organizar,

18. Loomie, 1974, p. 225, nota 23.

19. Cresuelo, carta del 29 de marzo de 1597, párrafo 7.

20. Cresuelo, carta del 28 de marzo de 1597, párrafo dos.

21. Cresuelo, carta del 29 de marzo de 1597, párrafo uno.

22. Mariana, La dignidad real y la educación del rey, p. 1 (nota del traductor) 
ordenar, regular y gobernar ${ }^{23}$. Se explica, pues, por qué otras traducciones al español tengan títulos como Del rey y de la institución de la dignidad real y Del rey y de la institución real.

En su prólogo al príncipe Felipe ${ }^{24}$, Mariana indica que segmenta su libro en tres partes. En la primera, resume el origen de la potestad real (por ende, la institución real), los límites del poder monárquico y su comparación con la tiranía. Esta sección es histórica, informativa y sucinta. En la segunda, estipula «como han de ser formados los príncipes desde sus primeros años [...] para la dirección de los negocios públicos» ${ }^{25}$. Esta sería la división propiamente didáctica, la cual versa sobre la instrucción real y el género literario de speculum principum. La tercera sección es teórica y versa sobre «cómo debe ser gobernado el Estado en tiempo de paz y defendido en tiempo de guerra» ${ }^{26}$. Para este propósito se vale de numerosos ejemplos históricos y «de la más profunda filosofía» ${ }^{27}$. Aunque hay puntos de contacto entre las tres partes, sobre todo entre la segunda (la didáctica) y la tercera, ésta última es especulativa y en efecto tiene que ver con la conservación del reino, tema más afín al de los tratados políticos que al más específico y acaso limitado de los specula ${ }^{28}$. De rege et regis institutione es pues una obra mixta-de «discursive hybridity» en la opinión del historiador Braun-29, o sea, 1) histórica (primer libro) 2) didáctica (segundo) y 3) especulativa (tercero), con funciones e incluso destinatarios disímiles.

Esta función múltiple explica por qué la sección sobre el tiranicidio $(1,6)$ del primer libro no parece estar contundentemente desarrollada ${ }^{30}$, ni aparenta ser teóri$\mathrm{ca}^{31}$. Aquí, el jesuita solo demuestra lo que puede ocurrir cuando el rey no es reconocido como tal: «La potestad del príncipe es muy débil cuando pierde el respeto de sus vasallos» ${ }^{32}$. Por formar parte la discusión del tiranicidio, Mariana usa un ejemplo reciente, el de Enrique III de Francia, acuchillado por el dominico Jacobo Clemente el 2 de agosto de 1589. Aunque hay una larga tradición político-teológica sobre el tiranicidio, Mariana simplemente no la elabora: su propósito no es plantear una teoría sino recordar lo que ocurre si se pierde «la tranquilidad pública», que es

23. Ver Lewis, 1915, p. 427.

24. Mariana, La dignidad real y la educación del rey, pp. 3-16.

25. Mariana, La dignidad real y la educación del rey, p. 14

26. Mariana, La dignidad real y la educación del rey, p. 14.

27. Mariana, La dignidad real y la educación del rey, p. 14

28. Nederman, 1998, p. 20, cita una definición de Einmar Már Jónsson sobre los specula principum o regale medievales («A Fürstenspiegel is a tract written for a prince [. . .] which has the principal object of describing the ideal prince, his comportment, his role, and his situation in the world»), y distingue así la función de un espejo o Fürstenspiegel y lo que él llama «political ethics» (p. 20).

29. Braun, 2008, p. 83.

30. Según Lauer, 1987, pp. 65-69, la mejor elaboración de este concepto es la de Francisco Suárez, S. J. 31. Braun, 2011, p. 28, opina que Mariana presenta en De rege «an ill-conceived theory of regicide». En su opinión, Mariana «presses his points about the ultimate non-juridical nature of early modern politics and true sovereignty [. . . ]. It also confirms that the notion of informal (non-juridical and non-constitutional) negotiation of power was as much part of the vibrant political landscape and discourse of early modern Spain as were the doctrines of contractualismo» (gobierno mixto) [p. 41].

32. Mariana, La dignidad real y la educación del rey, p. 71 
«el más precioso don del Estado» ${ }^{33}$. Aunque Mariana distingue entre tyrannus absque titulo (usurpador) y tyrannus in regimine (opresor) y nota que tradicionalmente se puede despojar al primero y tolerar al segundo ${ }^{34}$, ambos pueden convertirse en enemigos públicos y ocasionar subsiguientes guerras. El tiranicidio o regicidio que resultara ocurriría pues en un estado de guerra o de defensa propia, o sea, como una reacción de la ley natural. Por ende, el acto no diferenciaría entre uno y otro tirano. Sorprende que Mariana, a pesar de su atribución en Francia e Inglaterra de ser un supuesto "monarcómaco", opine que aun en el caso de defensa propia y en pleno acto de guerra sería inapropiado agredir contra un rey injusto o tiránico. Considera que David habría sido culpable de impiedad y no de amor al bien público si hubiera asesinado al rey Saúl, pues tenía la opción de fugarse para proteger su vida. Difiere así de la opinión de San Agustín en Contra Dimano (cap. 17), quien sugiere que David no quiso matar a Saúl «aunque le estaba permitido» ${ }^{35}$. Su opinión es que el príncipe debe gobernar virtuosa y justamente y no trastornar la religión patria, como hizo Enrique III. Esa idea no sería diferente de otros specula principum como De clementia de Séneca o el Basilikon doron del rey Jacobo, quienes advierten a sus respectivos destinatarios, Nerón y el príncipe Enrique, que los tiranos suelen morir asesinados con el aplauso de todo el mundo ${ }^{36}$. Es esta una descripción, un hecho, no un fallo o prescripción.

Asimismo, es curioso notar que aunque Mariana indica que trastornar la religión del reino puede constituir una razón para que un príncipe pueda ser considerado tirano, su opinión sobre la religión varía ${ }^{37}$. En la parte histórica, un cambio de fe puede causar una tiranía, como demuestran los anales; por ende, mantener una religión, la cristiana en este caso, sería un acto loable. En la parte didáctica (libro II, cap. 14), sin embargo, Mariana considera la religión no en forma prominente sino práctica, como un «consuelo en las horas adversas y de freno en las favorables para que no nos confiemos y abusemos de la prosperidad para nuestro daño» ${ }^{38}$. Mariana se da cuenta de que «Hay en el corazón del hombre muchísimas dobleces» y solo cumpliremos nuestras promesas si «estamos firmemente persuadidos de que cuida el cielo de castigar nuestros fraudes y delitos» ${ }^{39}$. Además, la religión sirve para procurar a los príncipes el amor y el celo de sus súbditos ${ }^{40}$. Sin ningún cinismo Mariana exhorta a Felipe III a valerse pues de la religión: «Ten, pues, joh dulcísimo príncipe!, por seguro que en el cultivo de la religión se encierra el más cierto apoyo

\footnotetext{
33. Mariana, La dignidad real y la educación del rey, p. 77. Ver Lauer, 1995, p. 207, nota 11

34. Mariana, La dignidad real y la educación del rey, p. 79

35. Mariana, La dignidad real y la educación del rey, p. 82. Lauer, 1995, p. 207, nota 8, sugiere que el titubeo de Mariana respecto al problema teórico del tiranicidio parece indicar su inseguridad. Como praxis, el tiranicidio en la Europa del siglo XVI parecía haberse convertido en un rito, como señala Ranum, 1980. 36. La observación es de Lauer, 1995, p. 206, nota 15.

37. Merle, 2014, p. 97, observa que Mariana, quien requiere que un superior u hombres sabios y prudentes opinen quien podría considerarse tirano, no indica que éstos debieran ser eclesiásticos.

38. Mariana, La dignidad real y la educación del rey, p. 258 (II, 14).

39. Mariana, La dignidad real y la educación del rey, p. 261 (II, 14).

40. Mariana, La dignidad real y la educación del rey, p. 264 (II, 14)
} 
de los negocios públicos» ${ }^{41}$. Como se puede observar, estas recomendaciones son esencialmente instructivas, apropiadas para la parte pedagógica de De rege.

Por ende, no debiera sorprender que en la parte teórica Mariana presente la religión no como costumbre o recurso de control social sino como el medio éticopolítico más importante para evitar guerras y preservar la paz ${ }^{42}$. Mariana se da cuenta de que, por el temor de perder la salvación eterna, el amor humano a la religión puede ser más poderoso que los vínculos de sangre o la autoridad de los magistrados, como podría evidenciarse en las Guerras de Religión de Francia o en la Guerra Anglo-Española (ésta última todavía en marcha). Cambios de culto o muchos cultos causan daño público, conspiraciones y parcialidades, como «estamos presenciando en nuestro tiempos» ${ }^{43}$. Cuando hay diferentes cultos, la paz del reino se trastorna y el príncipe no puede gobernar acertadamente. A la vez, cuando hay facciones, enemigos exteriores ayudan a diferentes bandos, lo cual hace imposible la paz pública; esto último ocasiona el debilitamiento de los reinos, como ha sucedido en Francia y Alemania. Aunque Mariana especula que ciertas naciones han permitido varios cultos, como en el caso de los otomanos, en estos reinos no se les ha permitido a los creyentes de una fe no patria la participación en el gobierno o el uso de armas; además, se les ha impuesto a los mismos graves tributos. Otrosí, en Inglaterra y Ginebra, los católicos han sido perseguidos y se les ha prohibido profesar su fe. Por lo tanto, nada debe cambiarse en la religión para poder conservar la integridad del estado. Como se ve, la justificación de una religión única en este caso no es ni transcendental ni expediente sino de una índole especulativa: estamos ante una auténtica razón de estado, casi independiente de culto ${ }^{44}$. Aun así, Mariana postula que su opinión es personal y que puede haber otras e incluso mejores opiniones. Su posición es especulativa, no doctrinal. Su texto sirve para recordar «a quien nos lea» (ya no solo el príncipe Felipe sino un destinatario plural y tácito) cómo es la condición humana; por ende, su finalidad es «prestar un servicio al bien público» ${ }^{45}$. Termina así el tercer libro de De rege, obra histórica, instructiva y política; texto de múltiples funciones y para heterogéneos destinatarios.

El último texto que nos ocupa es «A Letter Written to the Ambassador from England» del jesuita inglés Joseph Creswell («Cresuelo») al embajador Sir Charles Cornwallis (1555-1629). La «Carta escrita al embaxador de Inglaterra», en la posterior traducción al español en 1606, es una petición de tolerancia religiosa para los católicos ingleses; a la vez, es una insinuación al rey de la ahora Gran Bretaña

41. Mariana, La dignidad real y la educación del rey, p. 265 (II, 14).

42. Este pensamiento no difiere del de los Discursos (Discorsi sopra la prima deca di Tito Livio) de Maquiavelo, sobre todo el libro I, capítulo 11, donde se valora el aspecto civilizador de la religión (pagana) de los romanos en tiempos de Numa Pompilio (Machiavelli, The Discourses, p. $139[1,11]$ ).

43. Mariana, La dignidad real y la educación del rey, p. 444 (III, 17).

44. No sorprende que Mariana-a diferencia de otros pensadores de la época como Juan Márquez (como observa Braun, 2008, p. 90), quien se concentra más en lo religioso-político que en lo políticamente pragmático en su obra El gobernador cristiano (Salamanca 1612)-postule que los hombres nuevos o conversos sean incorporados al Estado y así evitar bandos y guerras civiles (Mariana, La dignidad real y la educación del rey, pp. 306-308 [III, 4]).

45. Mariana, La dignidad real y la educación del rey, p. 462 (III, 17). 
(Inglaterra, Escocia e Irlanda) de que cambie la dirección de la Iglesia en el Reino Unido, así como una disculpa de la actividad militar de España en Inglaterra durante la Guerra Anglo-Española (1585-1604). Su carta es una insigne muestra de diplomacia escrita en España un año después de la así llamada «Traición Jesuítica» o «Gunpowder Plot» del 5 de noviembre de 1605. La «Conspiración de la Pólvora», planeada por trece católicos, proyectaba explosionar la sede del Parlamento inglés. Se suponía que tanto el rey Jacobo I de Inglaterra e Irlanda y VI de Escocia, como su heredero, el príncipe Enrique, morirían en la explosión. Posteriormente, los insurgentes tenían la intención de colocar a la princesa Isabel de Estuardo, segunda hija del rey Jacobo, en el trono inglés, asegurándose así una sucesión católica en esos reinos. La conjuración falló y el rey impuso a sus vasallos católicos adicionales estatutos penales a los anteriormente impuestos por Isabel I en 1559. El contexto histórico de la carta afecta la petición moderada de Creswell.

La epístola contiene 98 párrafos numerados. Después de una breve alusión al padre jesuita Henry Garnet, ejecutado por su supuesta colaboración en el complot, Cresuelo le recuerda al embajador que los católicos ingleses aman a su soberano Jacobo I, a quien ven como un padre que, después del reinado de Isabel I, gobernaría con amor y justicia. Cresuelo también rememora que el anterior rey de España, Felipe II, nunca habría intentado tomar posesión de Inglaterra aunque la Grande y Felicísima Armada de 1588 hubiera triunfado. Su único interés había sido remediar las injurias cometidas por piratas ingleses y holandeses rebeldes en España y las Indias. Obviamente, estamos aquí ante una captatio y una apología: elementos necesarios para este tipo de documento. Con gran acierto diplomático, Cresuelo nunca acusa directamente al rey ni a sus antepasados de la violencia contra los católicos, agriada, obviamente por la conspiración de 1605. Tanto Enrique VIII46 como Isabel 147 fueron seducidos por consejeros y aduladores para romper la unidad de la Iglesia y entablar amistad con rebeldes religiosos. Tales nobles son enemigos de la paz ${ }^{48}$. A la vez, a pesar de la lealtad de los católicos en Inglaterra, ellos, como recusantes, han sufrido más que otros grupos religiosos auténticamente rebeldes, v. g., los luteranos, los Geuzen, los calvinistas, los hugonotes y los puritanos ${ }^{49}$.

Cresuelo hace comparaciones y contrastes notables entre el Reino Unido e imperios anteriores. En un ejemplo negativo, la situación en Inglaterra sería similar a la del imperio romano bajo Juliano el Apóstata ${ }^{50}$, cuando los católicos también fueron perseguidos. No obstante, bajo el emperador Augusto, conspiradores como Lucio Cornelio Cina, en lugar de ser castigados por su deseo de asesinar al emperador, fueron incorporados al imperio, asegurándose así su amor y lealtad para siempre ${ }^{51}$. Cresuelo pide fin a la persecución de los católicos en Inglaterra52, similar a la paz

\footnotetext{
46. Creswell, «A Letter Written to the Ambassador from England», p. 95.

47. Creswell, «A Letter Written to the Ambassador from England», p. 48.

48. Creswell, «A Letter Written to the Ambassador from England», p. 51.

49. Creswell, «A Letter Written to the Ambassador from England», p. 71.

50. Creswell, «A Letter Written to the Ambassador from England», p. 63.

51. Creswell, «A Letter Written to the Ambassador from England», pp. 86-89.

52. Creswell, «A Letter Written to the Ambassador from England», p. 59.
} 
establecida en Francia por Enrique IV53. Los católicos no se sublevarán en masa contra el rey, a pesar de unos cuantos rebeldes complotistas que no representan la opinión general de sus correligionarios, aunque sí un posible malcontento que pudiera resultar en la potencial inquietud del reino (nótese aquí una velada amenaza o cauta advertencia). Los católicos, como demuestra la historia, sufrirán pacientemente a quienes los atormentan, a quienes compadecen con amor y resignación ${ }^{54}$, ya que no han perdido la esperanza de que Dios restaurará la fe de sus antepasados: «He will restore our ancestors faith, honor and vertue to prevaile againe in that kingdome, as it was wont in their happye dayes» ${ }^{55}$. Si acuden al papa, el único consejo del pontífice a los fieles ingleses será recomendar que concedan a César lo que es de César y a Dios lo que es de Dios. No podría sugerir otra cosa ${ }^{56}$.

La petición de tolerancia de Creswell es la de un extranjero o peregrino (ya no un inglés o español) que transita, por tiempo limitado, en este mundo de Dios: «Yea, to speake more properly, the whole world is Gods possession, wherein I ame a stranger and a pilgrime for some fewe dayes, passing through it apace as my forefathers have done» ${ }^{57}$. Pero nótese también que es una leve insinuación a cambiar la religión del reino, una apología por los actos de agresión o defensa de España y una velada amenaza o cauta advertencia. En su despedida, Creswell/Cresuelo desea al rey y al embajador lo que él desearía para sí mismo: «truth, light and Gods grace in this life and afterwardes ever lasting felicyty» ${ }^{58}$. Aunque sea esta una diplomática captatio, la despedida insinúa de nuevo el deseo de que el rey se reconcilie con la Iglesia para poder gozar después de la buena andanza prometida a los fieles. Si esta interpretación fuera inabordable, entonces la epístola de Creswell fortalecería, al menos en sus buenos deseos, la legitimidad espiritual del Rey.

Como complemento, en una carta anterior escrita en Valladolid el 20 de junio de 1605, Creswell le había pedido a Robert Cecil, Conde de Salisbury y Lord Tesorero del Reino, una petición similar, sobre todo después del fin de hostilidades entre España e Inglaterra: «this peace now so happely concluded»59. Tanto en esta última carta como en la de 1606, Creswell, quien en 1597 abogaba por la invasión

53. Creswell, «A Letter Written to the Ambassador from England», p. 90.

54. Creswell, «A Letter Written to the Ambassador from England», p. 60.

55. Creswell, «A Letter Written to the Ambassador from England», p. 96. El rey Jacobo, aunque era protestante, había sido bautizado como católico.

56. Creswell, «A Letter Written to the Ambassador from England», p. 98. En efecto, como apunta Loomie, 1993, p. 26, después de la Conspiración de la Pólvora de 1605, el cardenal Borghese, como Secretario de Estado, había recomendado a los nuncios apostólicos de Madrid y París que pidieran a los embajadores de Inglaterra que usaran templanza y moderación hacia los católicos ingleses.

57. Creswell, «A Letter Written to the Ambassador from England», p. 62. La cita en español de «loseph Cresuelo», «Carta Escrita al Embaxador de Inglaterra», en edición facsimilar, se puede ver en Loomie, 1993, fol. 17, E1 r: «Antes (para hablar mas propriamente) toda la tierra es de Dios, y yo peregrino y huesped para pocos dias pasando por ella, a priessa, como han hecho mis antepassados».

58. Creswell, «A Letter Written to the Ambassador from England», p. 98. En español: «verdad, luz, y gracia de Dios en esta vida, y despues la bienauenturança eterna: a la qual nos lleue el Señor que nos criò para ella» (fol. 48v).

59. Creswell, «A Letter of Joseph Creswell to Robert Cecil, Earl of Salisbury, 20 June 1605», p. 200. La alusión es a la Guerra Anglo-Española: 1585-1604. 
de Inglaterra, la conversión del Reino Unido al catolicismo y un cambio de régimen que favoreciera a la infanta Isabel Clara Eugenia, sus sucesores y los intereses de España, ahora, no como español («Cresuelo») ni como inglés (Creswell) sino como peregrino del mundo, intercede solo por sus correligionarios.

Por sus escritos podríamos acaso juzgar al jesuita inglés Arthur, después llamado Joseph Creswell y finalmente Joseph Cresuelo, como inestable e intrigante. Podríamos igualmente enjuiciar al jesuita español Juan de Mariana como un teórico belicoso («bellicose theorist») ${ }^{60}$, enemigo de demócratas (republicanos) y realistas por igual, como señala Alan Soons ${ }^{61}$. Podríamos también estimar que la Declaración de Guerra de 1595 de Enrique a Felipe no puede ser una auténtica declaración sino una expresión de hostilidades hacia un reino vecino, como así conjeturara el Rey Prudente. Podríamos finalmente colegir que la proclamación de 1597 de Felipe II a la armada española, o la promulgación de 1595 contra el príncipe de Bearne, son documentos ambiguos o quiméricos, pues la primera no intenta solo proteger a los católicos ingleses sino imponer un cambio de régimen; la segunda no procura una estricta acción humanitaria sino un cambio monárquico. En ambos casos se propone incluso a la misma sucesora: la infanta Isabel Clara Eugenia.

Asimismo, en ningún momento podríamos pensar que estas obras tuvieran un mensaje único e inalterable: la carta al embajador de Inglaterra no es solo una petición de tolerancia sino un reconocimiento de Creswell de la autoridad legítima de los reyes Jacobo I y Enrique IV (el Príncipe de Bearne de Felipe II). El De rege no es solo un libro de instrucción sino de historia y de ética política. El anuncio de Felipe II en 1597 de la formación de una armada es también una declaración de guerra y una petición de ayuda a los ingleses para el derrocamiento de la descomulgada Isabel I. Finalmente, la Declaración de guerra a España de Enrique IV no podría ser un acto formal a causa del título defectuoso o dudoso del emisor sino una apertura de hostilidades contra la acción humanitaria española. En tal caso, la carta de Felipe II a Enrique es y no es una declaración de guerra contra un magnate a quien no se le concede autoridad legítima.

A la vez, podemos observar que estos documentos van dirigidos no a destinatarios explícitos y únicos sino a receptores implícitos y múltiples. La carta al embajador de Inglaterra de Creswell es en efecto una petición indirecta al rey Jacobo y sus consejeros; a la vez, la traducción al español va dirigida a personas influyentes de Madrid, como señala Loomie ${ }^{62}$. El texto de Mariana intitulado De rege et regis institutione no va dirigido solo al príncipe Felipe, como se indica en el prólogo, sino, también, «a quien nos lea», como se señala en el último capítulo de la tercera parte ${ }^{63}$. Las cartas de Enrique a Felipe II, o las de Felipe II a la armada española y al Príncipe de Bearne son documentos escritos para ser divulgados ante múltiples destinatarios: amigos y enemigos por igual. 
Los susodichos documentos son y no son lo que aparentan ser; por ende, no son textos firmes o de un significado unívoco. Al contrario, son obras intencionadamente inestables y de múltiples significados posibles. Su contenido está destinado a crear varios efectos, propuestos y contradictorios, realizables e hipotéticos, según las circunstancias siempre mutables del momento histórico y de sus emisores y variados destinatarios. Estos textos no podrían considerarse 'fake news' (noticias con intenciones erróneas), 'propaganda' (informes hiperbólicos o sensacionalistas) o 'posverdades' (reportes con distorsiones deliberadas para la manipulación de un público); son 'epitextos'64: textos de misceláneas verdades, todas posibles y sujetas a cambio ${ }^{65}$. Reflejan un mundo inconstante, cuya verdad, siempre mudable, se capta in transitu. Estamos ante obras de gran discernimiento político, de sorprendente diplomacia y pragmatismo y de una reticencia justificadora extraordinaria. A diferencia de obras estéticas, cuyas impresiones, según Immanuel Kant, son 'indiferentes'66, estas composiciones ético-políticas crean una abundancia o un surplus de impresiones ${ }^{67}$, todas capitales, con consecuencias, a veces luctuosas, para sus emisores y receptores. Producen efectos perlocutivos, ${ }^{68}$ que son capaces de transformar la realidad actual, así como la anterior y la posterior. Estas son, pues, obras de ética o prudencia política69.

En un mundo variable, como el que se evidencia en Europa en los siglos XVI y XVII durante las Guerras de Religión de Francia (1562-1598) y la Guerra AngloEspañola (1585-1604), las contingencias potenciales podrían ser múltiples. La persona prudente tendría que escoger bien, pero solo en el momento apropiado, ya que la realidad es versátil y requiere constante discernimiento. Enrique de Navarra puede ser simultáneamente el príncipe de Bearne, un enemigo público, un tirano o el legítimo Rey de Francia. Todo depende de la percepción de reyes como Felipe II; jesuitas como Joseph Creswell; papas como Sixto V (quien lo declara hereje), Gregorio XIV (quien lo descomulga) o Clemente VIII (quien lo reconcilia a la fe); el reino de Francia, fragmentado en hugonotes o cristianos reformados, católicos modera-

64. Del prefijo griego غ̇лí, cuyo significado implica demasía, según Hamilton, p. 98.

65. En la terminología de Derrida, 1990, los textos escriturales dejan una traza (spur) [una ausencia o presencia] \{p. 130\}, o un suplemento (supplément) [p. 126] y así postergan o aplazan inevitablemente significados únicos. En la escritura estamos pues ante un eterno Aufhebung hegeliano (p. 131) donde afirmamos, negamos y subsumimos significados siempre inefables o líquidos, en estados de perenne diferencia/deferencia. Esto sería más obvio en textos de ética política.

66. Kant, Critique of Judgement, p. 39 (I, 2).

67. Un supplément (ver Derrida, 1990, p. 126).

68. Ver, por ejemplo, Pratt, 2005, p. 1349: «Finally, a speaker who performs an illocutionary act may also be performing a perlocutionary act; that is, by saying what he says, he may be achieving certain intended effects in his hearer in addition to those achieved by the illocutionary act».

69. Para Santo Tomás, Summa theologica, p. 835 (I-II, q. 58, a. 3, Reply Obj. 1), la prudencia es la única de las virtudes que es tanto moral (como la templanza, la fortaleza y la justicia) como intelectual (como el conocimiento científico, la sabiduría, el entendimiento y el arte). Navega, pues, entre dos aguas: las de las buenas costumbres y las de las contingencias. «Prudence is essentially an intellectual virtue. But considered on the part of its matter, it has something in common with the moral virtues: for it is right reason about things to be done, as stated above $(Q .57, A$. r). It is in this sense that it is reckoned with the moral virtues». 
dos y tolerantes, galicanos nacionalistas y católicos ultramontanos internacionalistas; otros reinos: España, Holanda e Inglaterra; e incluso regicidas como François Ravaillac. Todo dependerá no solo del discernimiento humano, sino también del instante histórico cuya proteica realidad necesariamente determinará cualquier acción. Por ende, los textos que nos ocupan podrían verse como obras cínicas de individuos caprichosos para públicos incautos o como obras circunspectas de personas precavidas para audiencias en potencia. Todo dependerá de nuestro acertamiento, discernimiento, sagacidad, tino y prudencia. Como diría Baltasar Gracián, S. J., en su Oráculo manual y arte de prudencia de 1647, hay que «[37] Conocer y saber usar de las varillas» ${ }^{70}$ (insinuaciones), «[58] Saberse atemperar» ${ }^{71}$ (adaptarse), «[108] Saberse ladear» ${ }^{72}$, «[224] Saber tomar las cosas» ${ }^{73}$, «[256] Ir siempre prevenido» ${ }^{74}$, «[288] Vivir a la ocasión» ${ }^{75}$ y ser, «[300] En una palabra, santo» ${ }^{76}$.

Las obras ético-políticas aquí estudiadas son pues textos multifacéticos y prudenciales que sirven en efecto para esgrimir diversas intenciones en casi cualquier ocasión; crean así realidades que posteriormente solemos llamar historia.

\section{BIBLIOGRAFÍA}

Benedict, Philip, «From Polemics to Wars: The Curious Case of the House of Guise and the Outbreak of the French Wars of Religion», Historein, 6, 2006, pp. 97-105.

Braun, Harald E., «Baroque Constitution and Hybrid Political Language: The Case of Juan de Mariana (1535-1624) and Juan Márquez (1565-1621)», Revista Canadiense de Estudios Hispánicos, 33.1, 2008, pp. 79-104.

Braun, Harald E., «"Lawless" Sovereignty in Sixteenth-Century Spain: Juan de Mariana's De rege et regis institutione», en Law and Sovereignty in the Middle Ages and the Renaissance, ed. Robert S. Sturges, Turnhout, Brepols, 2011, pp. 23-41.

Cresuelo, Joseph, «Carta Escrita al Embaxador de Inglaterra», en English Polemics at the Spanish Court: Joseph Creswell's Letter to the Ambassador from England, The English and Spanish Texts of 1606, ed. Albert J. Loomie, S. J., New York, Fordham University Press, 1993, pp. 105-198 (fols. 2r-48v).

Cresuelo, Joseph, «Con muchas y evidentes señales», carta del 29 de marzo de 1597, traducida al inglés por Matt Waldroop, Washington, D. C., Liber Antiquus, siete párrafos numerados, inédita.

\footnotetext{
70. Gracián, Oráculo manual y arte de prudencia, pp. 37-38.

71. Gracián, Oráculo manual y arte de prudencia, p. 134.

72. Gracián, Oráculo manual y arte de prudencia, pp. 161-162.

73. Gracián, Oráculo manual y arte de prudencia, p. 225.

74. Gracián, Oráculo manual y arte de prudencia, p. 240.

75. Gracián, Oráculo manual y arte de prudencia, p. 255.

76. Gracián, Oráculo manual y arte de prudencia, pp. 260-261.
} 
Cresuelo, Joseph, «El deseo que nuestro Señor me ha dado de la redención de Inglaterra», carta del 28 de marzo de 1597, traducida al inglés por Matt Waldroop, Washington, D. C., Liber Antiquus, veinte y tres párrafos numerados, inédita.

Creswell, Joseph, «A Letter of Joseph Creswell to Robert Cecil, Earl of Salisbury, 20 June 1605», en English Polemics at the Spanish Court: Joseph Creswell's Letter to the Ambassador from England, The English and Spanish Texts of 1606, ed. Albert J. Loomie, S. J., New York, Fordham University Press, 1993, pp. 199-201.

Creswell, Joseph, «A Letter Written to the Ambassador from England», en English Polemics at the Spanish Court: Joseph Creswell's Letter to the Ambassador from England, The English and Spanish Texts of 1606, ed. Albert J. Loomie, S. J., New York, Fordham University Press, 1993, pp. 43-104.

Derrida, Jacques, «Différence», en Critical Theory since 1965, ed. Hazard Adams y Leroy Searle, Tallahassee, University Presses of Florida, 1990, pp. 120-136.

Gracián, Baltasar, S. J., Oráculo manual y arte de prudencia, ed. Emilio Blanco, Madrid, Cátedra, 1997.

Hamilton, Henry R., A Greek-English Lexicon, London, Lockwood \& Co., 1871.

Henri IV, Declaration de Guerre faite par Henri IV, Roi de France a Philippe II, Roi d'Espagne, Paris, 16 Janvier 1595, en Corps universal diplomatique du droit des gens, ed. Jean Dumont, barón de Carels-Croon, Amsterdam/La Haye, P. Brunel/R. \& J. Wetstein/G. Smith/Henri Waesberge/Z. Chatelain/P. Husson/ Charles Levier, 1728, vol. 5, parte 1, pp. 512-513.

Kant, Immanuel, Critique of Judgement, trad. J. H. Bernard, New York, Hafner Publishing Company, 1972.

Lauer, A. Robert, «Medieval Antecedents in Juan de Mariana's Alleged Theory of Regicide», en Studies on Medieval Spanish Literature in Honor of Charles F. Fraker, ed. Mercedes Vaquero y Alan Deyermond, Madison, Hispanic Seminary of Medieval Studies, 1995, pp. 197-209.

Lauer, A. Robert, Tyrannicide and Drama: Part I: The Tradition of Tyrannicide from Polybius to Suárez; Part II: The Tyrannicide Drama in Spain from 1579 to 1698, Stuttgart, Franz Steiner Verlag Wiesbaden GMBHm, 1987.

Lesaffer, Randall, «Between Faith and Empire: The Justification of the Spanish Intervention in the French Wars of Religion in the 1590s», en International Law and Empire: Historical Explorations, History and theory of International Law, ed. Martti Koskenniemi, Walter Recha y Manuel Jiménez Fonseca, Oxford, Oxford University Press, 2017, pp. 101-122.

Lewis, Charlton T., An Elementary Latin Dictionary, New York/Cincinnati/Chicago, American Book Company, 1915. 
Loomie, Albert J., S. J., «Introduction», en English Polemics at the Spanish Court: Joseph Creswell's Letter to the Ambassador from England, The English and Spanish Texts of 1606, New York, Fordham University Press, 1993, pp. 1-39.

Loomie, Albert J., S. J., «Philip II's Armada Proclamation of 1597», Recusant History, 12, 1974, pp. 216-225.

Machiavelli, Niccolò, The Discourses, ed. Bernard Crick, trad. Leslie J. Walker, S. J., Harmondsworth, Penguin Books, 1983.

Mariana, Juan de, La dignidad real y la educación del rey (De rege et regis institutione), ed. Luis Sánchez Agesta, Madrid, Centro de Estudios Constitucionales, 1981.

Merle, Alexandra, «El De rege de Juan de Mariana (1599) y la cuestión del tiranicidio: ¿un discurso de ruptura?», Criticón, 120-121, 2014, pp. 89-102.

Nederman, Cary J., «The Mirror Crack'd: The Speculum Principum as Political and Social Criticism in the Late Middle Ages», The European Legacy: Toward New Paradigms, 3.3, 1998, pp. 18-38.

Philippe II, Declaration de Guerre faite par Philippe II, Roi d'Espagne à Henri IV, Roi de France, qu'il nomme Prince de Bearn, Brusselles, 7 de Mars 1595, en Corps universal diplomatique du droit des gens, ed. Jean Dumont, barón de Carels-Croon, Amsterdam/La Haye, P. Brunel/R. \& J. Wetstein/G. Smith/ Henri Waesberge/Z. Chatelain/P. Husson/Charles Levier, 1728, vol. 5, parte 1, pp. 515-516.

Pratt, Mary Louise, «Toward a Speech Act Theory of Literary Discourse», en Critical Theory since Plato, ed. Hazard Adams y Leroy Searle, $3^{a}$. ed., Boston, Thomson/Wadsworth, 2005, pp. 1344-1355.

Ranum, Orest, «The French Ritual of Tyrannicide in the Late Sixteenth Century», Sixteenth Century Journal, 11.1, 1980, pp. 63-82.

Soons, Alan, Juan de Mariana, Boston, Twayne, 1982.

Suárez, Francisco, S. J., Defense of the Catholic and Apostolic Faith against the Errors of Anglicanism, trad. Peter L. P. Simpson, New York, Lucairos Occasio Press, 2013, vol. 2. Disponible en <http://www.aristotelophile.com/Books/ Translations/Suarez\%20Defense\%20Whole.pdf>.

Thomas Aquinas, St., Summa theologica, trad. Fathers of the English Dominican Provinces, Westminster, Maryland, Christian Classics, 1981, vol. 2 (Ia Ilæ QQ. 1-114).

Usunáriz, Jesús M., «El asesinato de Enrique IV de Francia y la publicística española del siglo XVII», Bulletin Hispanique, 118.2, 2016, pp. 453-472.

Vázquez de Prada, Valentín, Felipe II y Francia (1559-1598): política, religión y razón de Estado, Pamplona, Ediciones Universidad de Navarra, 2004. 